\title{
Somaclones em batata identificados pelos descritores mínimos de broto
}

\author{
Potato somaclones identified by minimum descriptors sprout
}

\author{
Gisele Santiago ${ }^{I}$ Lia Rejane Silveira Reiniger II Joana Graciela Hanauer ${ }^{\text {II }}$
}

\section{RESUMO}

Este estudo objetivou verificar a estabilidade fenotipica das cultivares de batata 'Asterix'e 'Macaca', avaliar o efeito do tipo de explante (organogênese direta e indireta) e do tempo de subcultivo (12 e 70 meses) em meio nutritivo MS sobre a ocorrência de somaclones nas duas cultivares na produção de batata semente, mediante o emprego de sete descritores mínimos de broto. Em 'Asterix'e 'Macaca' ocorreram somaclones em quatro dos sete descritores, contudo, apenas no formato e pubescência da base do broto houve variação, simultaneamente, em ambas. Os dois genótipos são suscetíveis à ocorrência de variação somaclonal. Registrou-se somaclonesnos dois tempos de subcultivo nas duas cultivares. Diferente do amplamente registrado, identificaramse somaclones em segmentos apicais caulinares e nodais originados de organogênese direta em 'Asterix' e 'Macaca'.

Palavras-chave: variação somaclonal, estabilidade fenotípica, organogênese direta, número de subcultivos.

\section{ABSTRACT}

It was examined the phenotypic stability of potato cultivars 'Asterix' and 'Macaca', evaluated the effect of explant type (direct and indirect organogenesis) and subculture time (12 and 70 months) in MS nutrient medium on the occurrence of somaclonal variation in both cultivars in seed potato production through the use of seven minimum descriptors sprout. In 'Asterix' and 'Macaca' somaclones have occurred in four of the seven descriptors, however, only in the shape and in the base of the bud pubescence that somaclonal variation occurred simultaneously in both cultivars. Both genotypes are susceptible to the occurrence of somaclonal variation. It was identify the occurrence of somaclones both at 12 months and 70 months of subculture in both genotypes. Unlike the widely recorded, somaclones were identified in shoot apical segments and nodal segments derived from direct organogenesis in 'Asterix' and 'Macaca'.

Key words: somaclonal variation, phenotipic stability, direct organogenesis, number of subcultures.

\section{INTRODUÇÃO}

A cultura da batata (Solanum tuberosum L.) é propagada, principalmente, de forma vegetativa, por meio de tubérculos-semente que desempenham importante função na fixação do conteúdo genético, permitindo a formação de clones (FAVORETTO, 2011). A utilização de material propagativo durante ciclos repetidos, todavia, pode causar o acúmulo e transmissão de patógenos, tais como: fungos, bactérias e vírus, contribuindo para a degenerescência das cultivares (PEREIRA \& FORTES, 2004).

Em batata, a cultura de tecidos é utilizada para recuperar cultivares infectadas por vírus, pela micropropagação de plantas livres de vírus, obtidas após o cultivo de ápices caulinares. Considera-se que a técnica preserva a identidade do genótipo regenerado, uma vez que as células do meristema apical mantêm mais uniformemente a estabilidade genética (TORRES et al., 1998). No entanto, o cultivo in vitro pode conduzir à ampliação da variabilidade genética e epigenéticano material micropropagado, denominada variação somaclonal (LARKIN \& SCOWCROFT, 1981; BAIRU, 2011).

A batata cultivada passou por estreitamento da base genética, devido a eventos durante a domesticação (HAWKES, 1978), o que constitui um grande desafio para a identificação de genótipos com caracteres superiores, devido às diferenças entre as cultivares serem, atualmente, menores. Por isso, as técnicas de cultivo in vitro podem contribuir para

\footnotetext{
'Departamento de Biologia, Universidade Federal de Santa Maria (UFSM), Av. Roraima, 1000, 97105-900, Santa Maria, RS, Brasil. E-mail: gisaplantbiotec@yahoo.com.br. Autor para correspondência.

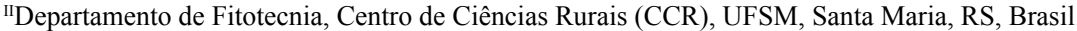
Recebido 10.04.14 Aprovado 27.11.14 Devolvido pelo autor 30.03.15 CR-2014-0557.R2
} 
gerar variabilidade ao material micropropagado, sendo necessário monitoramento para que possa ser empregado em programas de melhoramento genético vegetal.

Nesse sentido, os descritores mínimos, utilizados na caracterização e avaliação de acessos presentes em bancos de germoplasma, são amplamente empregados para diferenciar genótipos e são relacionados a uma série de características morfoagronômicas, de acordo com a espécie em questão (WETZEL et al., 2007; SILVA et al., 2013). A identificação de alterações em características morfológicas em plantas de batata provenientes da cultura de calos foi estudada, há bastante tempo, por alguns autores (RAMULU et al., 1983; BORDALLO et al., 2004). Existem evidências que, sob determinadas condições, plantas de cana-de-açúcar e de batata, oriundas de organogênese direta também apresentem variação somaclonal (ZUCCHI et al., 2002; ROSENBERG et al., 2010; SANTIAGO et al., 2012).

A continuidade de estudos relacionados à variação somaclonal em batata nas cultivares 'Asterix' e 'Macaca' é significativa no contexto socioeconômico nacional e da região central do Estado do Rio Grande do Sul. O presente estudo objetivou verificar a estabilidade fenotípica das cultivares de batata 'Asterix' e 'Macaca', avaliar o efeito do tipo de explante e do tempo de subcultivo sobre a ocorrência de somaclones nas duas cultivares na produção de batata semente, mediante emprego de descritores mínimos de broto.

\section{MATERIAL E MÉTODOS}

Os tubérculos de batata (Solanum tuberosum L.) das cultivares 'Asterix' e 'Macaca', utilizados para o isolamento dos ápices caulinares,que deram início aos ensaios descritos no presente estudo, foram previamente indexados para as principais viroses. Esses materiais foram cedidos pela Embrapa Clima Temperado, localizada em Pelotas, RS.

Os ensaios in vitro compreenderam quatro etapas, as quais foram conduzidas de maneira independente para as duas cultivares. Em todas as etapas, o cultivo foi conduzido em sala de cultivo com temperatura de $25^{\circ} \pm 3^{\circ} \mathrm{C}$, intensidade luminosa de $20 \mu \mathrm{mol} \mathrm{m} \mathrm{m}^{-2} \mathrm{~s}^{-1}$ e fotoperíodo de $16 \mathrm{~h}$ fornecido por lâmpadas fluorescentes brancas frias tipo luz do dia.

A primeira etapa foi constituída pelo isolamento de ápices caulinares, de cerca de $0,3 \mathrm{~cm}$, a partir de tubérculos cujo plantioem substrato havia ocorrido, aproximadamente, vinte e cinco dias antes. Esses ápices foram imediatamente inoculados em meio nutritivo MS (MURASHIGE \& SKOOG,
1962), na ausência dereguladores de crescimento, acrescido de sacarose $\left(30 \mathrm{~g} \mathrm{~L}^{-1}\right)$, mio-inositol (100mg $\left.\mathrm{L}^{-1}\right)$, ágar $\left(6 \mathrm{~g} \mathrm{~L}^{-1}\right)$ e em $\mathrm{pH} 5,7$. Os ápices caulinares foram mantidos in vitro por um período de 90 dias, sendo recultivados a cada 30 dias para meio nutritivo com a mesma composição citada acima.

$\mathrm{Na}$ segunda etapa, ocorreu o subcultivo das brotações obtidas a partir do cultivo de segmentos apicais caulinares regenerados na etapa anterior, que foi realizada em meio nutritivo MS, acrescido dos fitorreguladores: 6-Benzilaminopurina (BAP) (1mg $\left.\mathrm{L}^{-1}\right)$; Ácido $\alpha$-Naftaleno Acético (ANA) $(0,01 \mathrm{mg}$ $\left.\mathrm{L}^{-1}\right)$; e Ácido giberélico $\left(\mathrm{GA}_{3}\right)\left(0,1 \mathrm{mg} \mathrm{L}^{-1}\right)$. A partir do cultivo inicial de 90 dias, a cada 30 dias, as culturas foram subcultivadas, separando-se, em frascos diferentes, os segmentos apicais caulinares e os segmentos nodais originados por organogênese direta, bem como aqueles formados a partir de calos. Estes últimos, doravante neste artigo, serão denominados derivados de calo. Foram efetuados 12 (clone novo) e 70 (clone velho) subcultivos, sendo as subculturas inoculadas em meio fresco de igual composição àquela empregada no subcultivo inicial. Os ensaios das duas cultivares foram conduzidos de maneira independente, em delineamento inteiramente casualizado, em esquema bifatorial $2 \times 3$, sendo avaliados dois tempos de subcultivo (clone novo e velho)etrêstipos de explante(segmentoapical caulinar, segmento nodal e derivado de calo), que originaram as plantas da primeira geração clonal e os brotos dos seus tubérculos foram avaliados no presente estudo.

$\mathrm{Na}$ sequência, foram conduzidas as duas últimas etapas: indução e desenvolvimento radicular nas brotações, em meio nutritivo de igual composição àquele empregado na cultura de ápices caulinares; e aclimatização in vitro das plantas obtidas. Esta foi realizada pela transferência das plantas para meio nutritivo MS de composição idêntica à usada no enraizamento, mas com o teor de sacarose reduzido para 1,5\%, e abertura gradativa da vedação do frasco, diariamente, durante 15 dias, até a retirada total da tampa.

Depois de aclimatizadas, as plantas foram transferidas, no outono de 2005, para vasos de 1,3L de capacidade, contendo substrato Plantmax ${ }^{\circledR} \mathrm{e}$ cultivadas em casa devegetação. Nesse ambiente, foram produzidos tubérculos regenerantes da geração inicial $\left(\mathrm{R}_{0}\right)$, os quais, após colhidos, foram armazenados em câmara refrigerada, a $20^{\circ} \mathrm{C}$, até a implantação dos ensaios em campo.

Os subcultivos, o enraizamento, a aclimatização das plantas e a produção de tubérculos regenerantes de primeira geração $\left(R_{0}\right)$ foram efetuados 
preservando-se a identidade dos tratamentos. O plantio dos tubérculos $\mathrm{R}_{0}$ foi realizado na primavera de 2005. As plantas foram cultivadas no campo, em parcelas de 30 covas espaçadas a $0,30 \mathrm{mx} 0,80 \mathrm{~m}$ e manejadas de acordo com as recomendações para a cultura (PEREIRA et al., 2005). Os ensaios foram efetuados em área experimental, localizada em Santa Maria, RS, Brasil (latitude: $29^{\circ} 43^{\prime} \mathrm{S}$, longitude: $53^{\circ} 48^{\circ} \mathrm{W}$ e altitude: $95 \mathrm{~m}$ ). Segundo a classificação Köppen, o clima da região é do tipo Cfa, subtropical úmido, com verões quentes e sem estação seca definida (KUINCHTNER \& BURIOL, 2001). O solo do local é uma transição entre Argissolo VermelhoAmarelo distrófico arênico e Argissolo BrunoAcinzentado alíticoúmbrico (STRECK et al., 2008).

As avaliações foram feitas em 10 tubérculos regenerantes de segunda geração $\left(R_{1}\right)$, por tratamento, em exatos 90 dias após a colheita, conforme estabelecido por COLLARES (2002). Para cada característica, foi atribuída uma nota, de acordo com a escala estabelecida pelo Ministério de Agricultura, Pecuária e Abastecimento (MAPA), sendo avaliados: formato, coloração da base, intensidade da coloração da base, pubescência da base, aspecto do ápice, intensidade de primórdios radiculares e comprimento da brotação lateral. A metodologia para identificação dos somaclones encontra-se descrita em SANTIAGO et al. (2012).

Após testar a normalidade dos dados pelo teste de Kolmogorov-Smirnov e a homogeneidade de variâncias pelo teste de Bartlett, as variáveis foram transformadas para a função $\sqrt{x+0,5}$, sempre que necessário, e submetidas à análise de variância. As médias foram comparadas pelo teste de Tukey $(\mathrm{P}<0,05)$. A precisão do experimento foi medida por meio da estatística acurácia seletiva (AS), calculada por $\sqrt{1-1 / F c a l}$. Utilizou-se o programa estatístico SISVAR (Sistema para Análise de Variância) para Windows ${ }^{\circledR}$, versão 4.0 (FERREIRA, 2008). As médias observadas para cada característica morfoagronômicaforam comparadas às notas atribuídas às cultivares em suas respectivas descrições e somente foram consideradas variantes somaclonais as médias que foram enquadradas em uma classe fenotípica diferente do padrão da cultivar respectiva.

\section{RESULTADOS E DISCUSSÃO}

Em 'Asterix' e 'Macaca', foram observadas variantes somaclonais para quatro dos sete descritores morfoagronômicos avaliados, sendo que apenas no formato e pubescência da base do broto ocorreu variação somaclonal, simultaneamente, nas duas cultivares. Em trabalho anterior, SANTIAGO et al. (2012) identificaram somaclones para as cultivares 'Asterix' e 'Macaca' em quatro e dois dos seis descritores morfoagronômicos avaliados, respectivamente. Contudo, apenas no formato e cor da polpa do tubérculo ocorreu variação somaclonal, simultaneamente, nas duas cultivares.

As duas cultivares apresentaram diferenças quanto à estabilidade fenotípica das características morfoagronômicas, após cultura de tecidos, indicando que a variação somaclonal é influenciada pelo genótipo, ratificando a tese de que esse fenômeno afeta diferencialmente cultivares de uma mesma espécie (SKIRVIN et al., 1994). Essa diferença na estabilidade fenotípica já foi registrada em algumas cultivares de batata e morangueiro (Fragaria $x$ ananasa Duch.). Em batata, BORDALLO et al. (2004) avaliaram a estabilidade de genótipos para a produção de sementes sintéticase constataram que, dentre as cinco cultivares avaliadas, 'Baronesa' apresentou o mais alto nível de variação somaclonal e 'Contenda', o menor. Em morangueiro, FONSECA et al. (2013) submeteram as cultivares 'Aromas', 'Camarosa' e 'Camino Real' a três e doze ciclos de subcultivos in vitro, a fim de verificar a estabilidade fenotípica dessas cultivares, e concluíram que a cultivar 'Aromas' apresentou maior estabilidade nas características fenotípicas avaliadas. Também em morangueiro, BISWAS et al. (2009) selecionaram três somaclones promissores através de estabilidade diferencial de fenótipos para características florescimento e tamanho de fruto.

No presente trabalho, em todos os descritores em que houve algum efeito significativo, observaram-se valores muito altos $(\geq 0,9)$ de acurácia seletiva, de acordo com a classificação proposta por RESENDE \& DUARTE (2007). Portanto, houve alta precisão no acesso do verdadeiro valor genético dos tratamentos nas avaliações, uma vez que a correlação entre os valores fenotípicos observados e os preditos, para aquelas características em que houve variabilidade, foi muito alta.

$\mathrm{Na}$ análise do efeito dos explantes e tempos de subcultivo, observaram-se, também, diferenças entre as cultivares estudadas. Em 'Asterix', verificouse interação significativa entre os fatores principais para formato do broto e, também, para pubescência da base do broto, ocorrendo, em ambos os descritores, divergência do fenótipo original da cultivar. Os brotos deveriam apresentar formato oval (nota 2), entretanto, as médias variaram de 1,80 a 2,60, correspondendo a esférico-oval, contudo, segundo o critério adotado, 
ocorreram somaclones apenas no clone novo de segmento apical caulinar, que foi classificado como esférico (Tabela 1). Quanto à pubescência da base do broto, plantas oriundas de derivado de calo e de segmento nodal de clone velho receberam nota 5,20 , equivalendo à pubescência média, diferindo do padrão da cultivar que possui pouca pubescência (nota 3) (Tabela 1).

$\mathrm{Na}$ cultivar 'Macaca', em relação ao formato do broto, houve efeito significativo apenas para o tempo de subcultivo, sendo que os clones novo (média 2,33) e velho $(2,67)$ diferiram entre si, mas seriam ambos classificados como ovais, contrastando do padrão, que é cilíndrico largo (nota 4). Quanto à pubescência da base do broto, os clones novo (média $3,93)$ e velho $(3,40)$ também diferiram entre si, e seriam classificados como pouco pubescentes (nota 3 ), divergindo do padrão (pubescência média, nota 5).

Por outro lado, o aspecto do ápice do broto manteve-se estável em 'Asterix' e 'Macaca". Em 'Asterix', diferentemente de 'Macaca', não foram identificados somaclones para intensidade de primórdios radiculares e comprimento da brotação lateral. Apenas em 'Macaca', não se observaram somaclones para coloração da base do broto e intensidade dessa coloração.

Em 'Asterix', observou-se interação significativa entre os fatores principais para a coloração da base do broto, intensidade dos primórdios radiculares e comprimento da brotação lateral. A coloração da base dos brotos de segmento apical caulinar no clone novo recebeu nota 1,80, divergindo do fenótipo padrão (vermelho-púrpura, nota 2), o que permite classificar os brotos como verde (nota 1) (Tabela 1). Nas duas últimas características, plantas oriundas de derivados de calo e de segmentos nodais dos clones novo e velho diferiram entre si, contudo, isso não resultou em modificação para outra categoria fenotípica (Tabela 1).

Em 'Macaca', para a coloração da base do broto e intensidade dessa coloração, ocorreram diferenças entre os níveis dos fatores principais, contudo, as notas observadas não implicaram uma classificação diferente do padrão descrito para a cultivar. Observaram-seque os clones novo e velho apresentaram médias 2,33 e 2,67 para coloração da base do broto, respectivamente, contrastando da nota 2 (equivalente a vermelho-púrpura), característica da

Tabela 1 - Médias das notas atribuídas ao formato do broto, coloração da base e pubescência da base do broto, intensidade de primórdios radiculares e comprimento da brotação lateral, oriundos de segmento apical caulinar (SAC), derivado de calo (DC) e segmento nodal (SN) nos clones novo (N) e velho (V) da cultivar de batata 'Asterix', Santa Maria - RS.

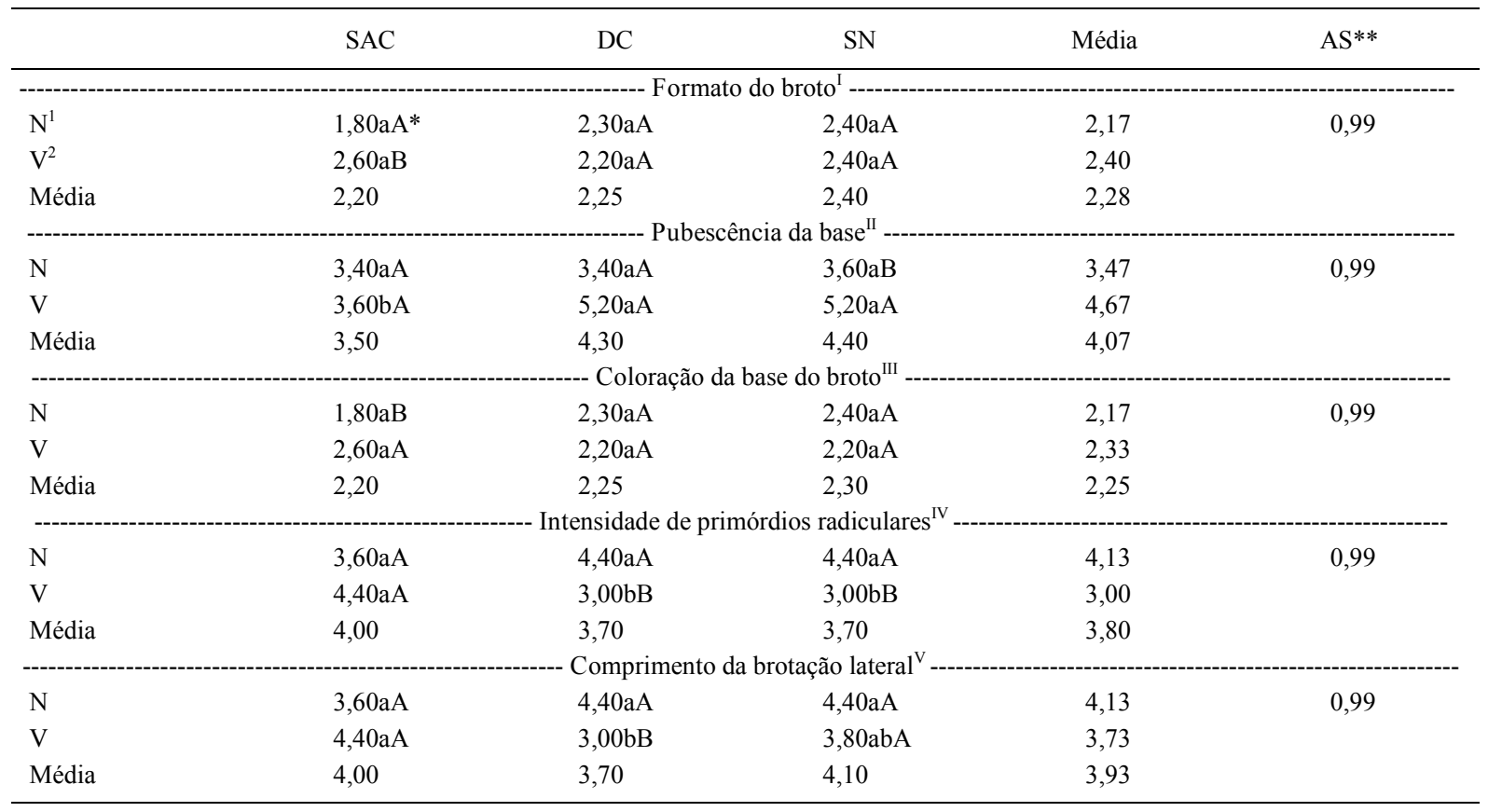

I oval (2); ${ }^{\mathrm{II}}$ pouca (3); ${ }^{\mathrm{III}}$ vermelho-púrpura (2); ${ }^{\mathrm{IV}}$ Baixa-média(3-5); ${ }^{\mathrm{V}} \mathrm{Curto}(3)$. ${ }^{1}$ Em subcultivo por 12 meses; ${ }^{2} \mathrm{Em}$ subcultivo por 70 meses; * Médias seguidas pela mesma letra, minúscula na linha e maiúscula na coluna, não diferem significativamente pelo teste de Tukey ( $\mathrm{P}<0,05$ ).

$* * \mathrm{AS}=$ acurácia seletiva (muito alta: $\geq 0,90 ;$ alta: $\geq 0,70$ e $<0,90 ;$ moderada: $<0,70$ e $\geq 0,50$ ). 
cultivar, mas não o suficiente para ser classificada como azul-púrpura (nota 3). Da mesma maneira, em relação aos explantes, plantas regeneradas de segmentos nodais receberam nota 2,37 , diferindo daquelas originadas de segmentos apicais caulinares (nota 2,95) e, também, dos derivados de calo, os quais foram avaliados como vermelho-púrpura (nota 2), típico da cultivar.

Quanto à intensidade da coloração da base do broto, em 'Macaca', houve interação entre o tempo de subcultivo e o tipo de explante, observandose alguns tratamentos que diferiram dos demais e apresentaram intensidade fraca (nota 3), mas não atingiram a nota 5 , equivalente à intensidade média. Plantas regeneradas a partir de segmentos apicais caulinares no clone velho foram os únicos que conservaram a nota 3, própria de 'Macaca'.

Em 'Asterix', não houve efeito significativo dos fatores principais nem da interação para a intensidade da coloração da base do broto. Entretanto, a característica teve média igual a 3,10 , indicando coloração fraca; houve, portanto, divergência em relação à descrição da cultivar, nota entre 5 e 7 , correspondendo à intensidade média-forte.

Em relação à intensidade da coloração da base do broto, SILVA et al. (2013) verificaram que essa característica contribui com $15,81 \%$ na diferenciação de um germoplasma de batata, sendo relevante para avaliação da dissimilaridade genética de cultivares em programas de melhoramento vegetal. Assim, a identificação de diferença em relação ao padrão da cultivar em 'Asterix' e manutenção do fenótipo em 'Macaca' contribuem para ratificar a tese de estabilidade diferencial entre cultivares ao passarem pelo cultivo in vitro, sugerindo a necessidade de adotar medidas diferentes para genótipos distintos.

$\mathrm{Na}$ cultivar 'Macaca', para a intensidade dos primórdios radiculares, segmentos apicais caulinares (nota 7) diferiram de derivados de calo (nota 6,20), mas segmentos nodais (nota 6,40) não diferiram de nenhum dos explantes anteriores; contudo, todos divergiram do fenótipo descrito para 'Macaca', de intensidade baixa (nota 3). O clone novo $(6,33)$, igualmente, diferiu do velho $(6,80)$ e ambos, do padrão de 'Macaca'. Para o comprimento da brotação lateral, da mesma maneira, segmentos apicais caulinares (nota 6,90) diferiram de derivados de calo (nota 6,30), mas segmentos nodais (nota $6,50)$ não diferiram dos outros dois; porém todos divergiram do padrão de 'Macaca' para o caráter, cuja nota é 3 , equivalente a comprimento curto.

No presente estudo, observou-se que a escolha do explante em função do grau de diferenciação para micropropagação não garantiu estabilidade fenotípica. Para segmentos apicais caulinares, em 'Asterix', verificou-se a ocorrência de variantes para formato do broto e coloração da base do broto, enquanto que em 'Macaca' identificaramse somaclones para intensidade de primórdios radiculares e comprimento da brotação lateral. Esses resultados vão de encontro à tese de que explantes como ápices caulinares são mais estáveis que explantes originados a partir de organogênese indireta (JAIN, 2001). O crescimento de células de plantas in vitro e sua regeneração em plantas inteiras é um processo assexuado, envolvendo apenas divisão mitótica e, teoricamente, não deveria causar qualquer variação (BAIRU et al., 2011). Entretanto, recentemente, ROSENBERG et al. (2010) demonstraram que clones de batata da cultivar 'Reet', originados de ápices caulinares, apresentaram variação somaclonal para características fenotípicas como rendimento. Em cana-de-açúcar, identificaram-se somaclones em genótipos originados de ápices caulinares (ZUCCHI et al., 2002).

Quanto ao tempo de subcultivo, observouse que, no período mínimo testado de 12 meses (12 subcultivos), ambas as cultivares apresentaram somaclones, demonstrando que o tempo de subcultivo adequado para manutenção da estabilidade fenotípica em'Asterix' e 'Macaca' foi excedido. Esses resultados vão ao encontro de que o tempo de 12 subcultivos não assegura estabilidade ao material micropropagado para fins de produção de batata semente (SANTIAGO et al., 2012). Em muitas culturas, que utilizam cultivo in vitro, constatou-se que o aumento no número de subcultivos e sua duração aumentaram a ocorrênciade variação somaclonal (BAIRU et al., 2011). Em culturas de Musas pp. (Grupo AAB), cultivar 'Pacovan', estabeleceu-se o limite de seis subcultivos para estabilidade fenotípica (SANTOS \& RODRIGUES, 2004). Muitos laboratórios comerciais têm adotado medidas práticas, como limitar o número de subcultivos, a partir de um explante, a um período de 12 meses, após o qual todas as culturas originadas a partir desse explante são descartadas (SKIRVIN et al., 1994). O emprego dos descritores morfológicos como ferramentas de acompanhamento de estabilidade fenotípica pode contribuir com programas de melhoramento, pois auxilia a identificar em campo a ocorrência de características desejáveis.

\section{CONCLUSÃO}

As cultivares de batata 'Asterix' e 'Macaca' são, igualmente, suscetíveis à ocorrência de variação somaclonal, porém esse fenômeno atua de maneira diferenciada em relação aos descritores mínimos de broto nas duas cultivares. Segmentos apicais caulinares e segmentos nodais, originados de organogênese direta ou indireta, são explantes igualmente instáveis para produção de batata semente 
nas condições específicas deste estudo. Doze meses de subcultivo já são suficientes para originar somaclones em ambas as cultivares de batata avaliadas, não sendo adequado para produção de batata semente. Os variantes somaclonais podem ser identificados, nas cultivares de batata 'Asterix' e 'Macaca', pelo uso dos descritores mínimos de broto.

\section{REFERÊNCIAS}

BAIRU, M.W. et al. Somaclonal variation in plants: causes and detection methods. Plant Growth Regulation. Disponivel em: $<$ http://www.springerlink.com/content/01t677688j110j15/>. Acesso em: 14 jan. 2011. doi:10.1007/s10725-010-9554-x.

BISWAS, M.K. et al. Development and avaluation of in vitro somaclonal variation in strawberry for improved horticultural traits. Scientia Horticulturae, v. 122, n.3, p.409-416, 2009. Disponível em: $<\mathrm{http}: / /$ www.sciencedirect.com/science/article/pii/ S030442380900288X>. Acesso em: 05 maio 2014. doi: 10.1016/j. scienta.2009.06.002.

BORDALLO, P.N. et al. Somaclonal variation on in vitro callus culture potato cultivars. Horticultura Brasileira, v.22, n.2, p.300-304, 2004. Disponível em: <http://www.scielo.br/pdf/hb/ v22n2/21035.pdf >. Acesso em: 02 set. 2013.

COLLARES, E.A.V.S. et al. Caracterização morfológica de cultivares e clones avançados de batata por descritores necessários à proteção legal. Pelotas: Embrapa Clima Temperado, 2002. 50p. (Documentos, 98).

EMBRAPA. Sistema brasileiro de classificação de solos. Brasília: Embrapa Produções de informações, 1999. 412p.

FAVORETTO, P. et al. Molecular characterization of potato cultivars using SSR markers. Horticultura Brasileira, v.4, n.29, p.542-547, 2011. Disponível em: <http://dx.doi.org/10.1590/ S0102-0536211000400017>. Acesso em: 20 mar. 2014.

FERREIRA, D.F. SISVAR: um programa para análises e ensino de estatística. Revista Symposium, v.6, p.36-41, 2008.

FONSECA, A.P. et al. Estabilidade fenotípica de genótipos de morangueiro submetidos a número variável de subcultivos in vitro. Ciência Rural, v.43, n.8, p.1345-1350, 2013. Disponível em: $<$ http://www.scielo.br/pdf/cr/v43n8/a21313cr2012-0325.pdf>. Acesso em: 18 set. 2013.doi: 10.1590/S0103-84782013005000096.

HAWKES, J.G. History of the potato. In: HARRIS, P.M. The potato crop: the scientific basis for improvement. London: Chapman \& Hall, 1978. p.1-14.

JAIN, S.M. Tissue cultured-derived variation in cropimprovement. Euphytica, v.118, n.2, p.153-166, 2001. Disponível em: <http:// www.springerlink.com/content/w51544k4108q3750/>. Acesso em: 02 maio 2009. doi:10.1023/A:1004124519479.

KUINCHTNER, A.; BURIOL, G.A. Clima do Estado do Rio Grande do Sul segundo a classificação climática de Köppen e Thornthwaite. Disciplinarum Scientia, v.2, n.1, p.171182, 2001. Disponível em: <http://sites.unifra.br/Portals/36/ tecnologicas/2001/clima.pdf>. Acesso em: 02 abr. 2014.

LARKIN, P.J.; SCOWCROFT, W.R. Somaclonal variation: a novel source of variability from cell cultures forplantimprovement. Theoretical and Applied Genetics, v.60, n.4, p.197-214, 1981. Disponível em: $<\mathrm{http}: / /$ www.springerlink.com/content/5140qq04260032k/>. Acesso em: 29 set. 2011. doi: 10.1007/BF02342540.

MURASHIGE, T.; SKOOG, F. A revised medium for rapid growth and bioassays with tobbaco tissue culture. Plant Physiology, v.15, p.473-497, 1962.

PEREIRA, J.E.S; FORTES, G.R.L. Organogênese de ápices meristemáticos de batata em meios de isolamento e multiplicação in vitro. Horticultura Brasileira, v.22, n.2, p.197201,2004. Disponível em: <http://dx.doi.org/10.1590/S010205362004000200007>. Acesso em: 22 mar. 2014.

PEREIRA, A.S. et al. Produção de batata no Rio Grande do Sul. Pelotas: Embrapa/CPACT, 2005. 14p. (Circular técnica 48).

RAMULU, K.S. et al. Phenotypic variation and ploidy level of plants regenerated from callus potato (Solanumtuberosum L. cv. 'Bintje'). Theoretical and Applied Genetics, v.65, n.4, p.329-338, 1983. Disponível em: 〈http://www.springerlink.com/content/gl34363703333357>. Acesso em: 08 maio 2011. doi: 10.1007/BF00276573.

RESENDE, M.D.V.; DUARTE, J.B. Precisão e controle de qualidade em experimentos de avaliação de cultivares. Pesquisa Agropecuária Tropical, v.37, n.3, p.182 -194, 2007.

ROSENBERG, V. et al. Somaclonal variation in potato meristem culture and possibility to use this phenomenon in seed potato production and breeding. Agronomy Research, v.8, n.3, p.697704, 2010. Disponível em: <http://www.eria.ee/public/files/ LAartikkel.pdf>. Acesso em: 18 set. 2013.

SANTIAGO, G. et al. Variação somaclonal nos descritores mínimos de tubérculo em batata. Ciência Rural, v.42, n.2, p.197202, 2012. Disponível em: <http://www.scielo.br/pdf/cr/v42n2/ a5312cr5306.pdf>. Acesso em: 20 mar. 2014. doi: 10.1590/ S0103-84782012000200002.

SANTOS, C.C.C.; RODRIGUES, P.H.V. Variação somaclonal em mudas micropropagadas de bananeira, cultivar 'Pacovan'. Bragantia, v.63, n.2, p.201-205,2004. Disponível em: <http://dx.doi. org/10.1590/S0006-87052004000200005>. Acesso em:29 jan. 2015.

SKIRVIN, R.M. et al. Sources and frequency of somaclonal variation. Hortscience, v.29, n.11, p.1232-1237, 1994.

SILVA, G.O. et al. Importância de caracteres para avaliação de um banco de germoplasma de batata. Brasília: Embrapa Hortaliças, 2013. 12p. (Boletim de Pesquisa e Desenvolvimento 90).

STRECK, E.V. et al. Solos do Rio Grande do Sul. Porto Alegre: EMATER/RS; UFRGS, 2002. 126p.

TORRES, L.S. et al. Cultura de ápices caulinares e recuperação de plantas livres de vírus. In: TORRES, A. (Ed.). Cultura de tecidos e transformação genética de plantas. Brasília: EMBRAPA-SPI/ EMBRAPA-CNPH, 1998. V.1, p.87-132.

ZUCCHI, M.I. et al. Genetic instability of sugarcane plants derived from meristem cultures. Geneticsand Molecular Biology, v.25, n.1,p.91-96, 2002. Disponível em: <http://www.scielo.br/ $\mathrm{pdf} / \mathrm{gmb} / \mathrm{v} 25 \mathrm{n} 1 / \mathrm{a} 17 \mathrm{v} 25 \mathrm{n} 1 . \mathrm{pdf}>$. Acesso em: 22 mar. 2014. doi: 10.1590/S1415-47572002000100017.

WETZEL, M. M. V. da S.; FERREIRA, F.R. Sistema de curadorias de germoplasma. In: NASS, L.L. (Ed.). Recursos genéticos vegetais. Brasília, DF: Embrapa Recursos Genéticos e Biotecnologia, 2007. 858p. 